\title{
Effectiveness of the capsaicin 8\% patch in the management of peripheral neuropathic pain in European clinical practice: the ASCEND study
}

Colette Mankowski ${ }^{1}$, Chris D. Poole ${ }^{1}$, Etienne Ernault ${ }^{2}$, Roger Thomas ${ }^{3}$, Ellen Berni $^{3}$, Craig J. Currie ${ }^{4}$, Cecil Treadwell ${ }^{1}$, José I. Calvo ${ }^{5}$, Christina Plastira ${ }^{6}$, Eirini Zafeiropoulou ${ }^{6}$ and Isaac Odeyemi ${ }^{1}$

\begin{abstract}
Background: In randomised studies, the capsaicin 8\% patch has demonstrated effective pain relief in patients with peripheral neuropathic pain (PNP) arising from different aetiologies.

Methods: ASCEND was an open-label, non-interventional study of patients with non-diabetes-related PNP who received capsaicin $8 \%$ patch treatment, according to usual clinical practice, and were followed for $\leq 52$ weeks. Co-primary endpoints were percentage change in the mean numeric pain rating scale (NPRS) 'average daily pain' score from baseline to the average of Weeks 2 and 8 following first treatment; and median time from first to second treatment. The primary analysis was intended to assess analgesic equivalence between post-herpetic neuralgia (PHN) and other PNP aetiologies. Health-related quality of life (HRQoL, using EQ-5D), Patient Global Impression of Change (PGIC) and tolerability were also assessed.

Results: Following first application, patients experienced a 26.6\% (95\% Cl: 23.6, 29.62; $n=412$ ) reduction in mean NPRS score from baseline to Weeks 2 and 8. Equivalence was demonstrated between PHN and the neuropathic back pain, post-operative and post-traumatic neuropathic pain and 'other' PNP aetiology subgroups. The median time from first to second treatment was 191 days (95\% Cl: 147, 235; $n=181$ ). Forty-four percent of all patients were responders ( $\geq 30 \%$ reduction in NPRS score from baseline to Weeks 2 and 8) following first treatment, and $86.9 \%(n=159 / 183)$ remained so at Week 12. A sustained pain response was observed until Week 52, with a $37.0 \%(95 \% \mathrm{Cl}: 31.3,42.7 ; n=176)$ reduction in mean NPRS score from baseline. Patients with the shortest duration of pain ( $0-0.72$ years) experienced the highest pain response from baseline to Weeks 2 and 8. Mean EQ-5D index score improved by 0.199 utils (responders: 0.292 utils) from baseline to Week 2 and was maintained until Week 52. Most patients reported improvements in PGIC at Week 2 and at all follow-up assessments regardless of number of treatments received. Adverse events were primarily mild or moderate reversible application site reactions.
\end{abstract}

Conclusion: In European clinical practice, the capsaicin 8\% patch provided effective and sustained pain relief, substantially improved HRQoL, improved overall health status and was generally well tolerated in a heterogeneous PNP population.

Trial registration: NCT01737294 Date of registration - October 22, 2012.

Keywords: Capsaicin 8\% patch, Neuropathy, Pain management, Peripheral neuropathic pain, Topical analgesic, Numeric pain rating scale, Health-related quality of life

* Correspondence: etienne.ernault@astellas.com

${ }^{2}$ Astellas Pharma Europe B.V., Leiden, The Netherlands

Full list of author information is available at the end of the article 


\section{Background}

Peripheral neuropathic pain (PNP) is caused by a lesion or disease involving the somatosensory system [1]. Common causes of PNP include traumatic nerve injury, surgery, diabetes, herpes zoster infection, cancer, chemotherapy and human immunodeficiency virus (HIV) infection [2]. PNP affects $7-8 \%$ of the population in Europe $[3,4]$ and can negatively impact quality of life, psychological wellbeing, sleep and work productivity [5].

The latest treatment guidance from the Neuropathic Pain Special Interest Group (NeuPSIG) of the International Association for the Study of Pain recommends several options for first line treatment of neuropathic pain (NP), including calcium $\alpha_{2}-\delta$ ligands (e.g. pregabalin, gabapentin), serotonin/norepinephrine reuptake inhibitors and tricyclic antidepressants [6]. Despite proven efficacy, these therapies have limitations including inadequate pain relief, lengthy dose-titration periods, multiple daily dosing, dose-limiting adverse events, suboptimal adherence due to adverse events, and the potential for abuse and addiction [7-9].

NeuPSIG guidance suggests tramadol, the lidocaine $5 \%$ patch and the $179 \mathrm{mg}(8 \% \mathrm{w} / \mathrm{w})$ capsaicin patch as second line treatment options for patients with neuropathic pain [6]. Capsaicin is a selective, potent and highaffinity agonist for the transient receptor potential vanilloid type 1 (TRPV1) ion channel complex [10]. Application of high-dose capsaicin at the site of pain can defunctionalise TRPV1 leading to disruption of mitochondrial respiration and retraction of the nerve fibres, thereby reducing the pain response [10]. Localised treatment with the capsaicin $8 \%$ patch limits the potential for drug-drug interactions and avoids the need for dose adjustment in the elderly or in patients with renal or hepatic impairment [11].

The capsaicin $8 \%$ patch has been shown to reduce pain compared with placebo for patients with postherpetic neuralgia (PHN), HIV-associated neuropathy (HIV-AN), and painful diabetic peripheral neuropathy [12-17]. In non-diabetic patients with a variety of PNP aetiologies, the capsaicin $8 \%$ patch demonstrated noninferior pain relief versus pregabalin, with a more rapid onset of pain relief and fewer systemic side effects [18]. The capsaicin $8 \%$ patch is generally well tolerated with treatment-related side effects mostly limited to application site reactions such as erythema $[12,14]$.

A 12-week, non-interventional study of a single capsaicin $8 \%$ patch treatment demonstrated effectiveness and suggested a benefit of early treatment within six months of diagnosis [19]. The aim of this non-interventional study was long-term monitoring (52 weeks) of nondiabetic patients with PNP undergoing treatment with the capsaicin $8 \%$ patch in a real-world setting. This work reports the efficacy, re-treatment pattern, tolerability and health-related quality of life (HRQoL) associated with capsaicin $8 \%$ patch treatment in Europe.

\section{Methods \\ Study design and participants}

The ASCEND study (NCT01737294) was a Phase 4, multi-centre, open-label, non-interventional study (NIS) conducted between February 2012 and August 2014 in accordance with the principles of the Declaration of Helsinki, International Conference on Harmonisation Guidelines, and local ethical and legal requirements.

Patients were eligible for inclusion if they were at least 18 years old, recommended capsaicin $8 \%$ patch treatment by their treating physician, diagnosed with non-diabetic PNP and had provided written informed consent for participation in the study. Patients were excluded for the following reasons: neuropathic painful areas located only on the face, above the hairline of the scalp and/or in proximity to mucous membranes; history of diabetes mellitus; diagnosis of any major psychiatric disorder, or evidence of cognitive impairment; prior treatment with capsaicin $8 \%$ patch; hypersensitivity to capsaicin, capsaicin $8 \%$ patch excipients/adhesives, and/ or local anaesthetics; participation in any other clinical study and/or receipt of an investigational drug within 30 days prior to screening visit; history of substance abuse (including alcoholism).

A detailed medical history was taken with particular emphasis on the primary PNP diagnosis. Patients were classified into one of six aetiology groups: PHN; HIV$\mathrm{AN}$; neuropathic back pain (NBP), including cases secondary to radiculopathy, polyneuropathy, plexopathy and ankylosing spondylitis; cancer-related neuropathic pain (CRNP); post-operative and post-traumatic neuropathic pain (PONP); 'other' neuropathies. Prior and concomitant medications were recorded at baseline and patients were categorised by the treating physician as being in the primary (first treatment received for NP), secondary (second treatment received for NP) or tertiary (at least third treatment received for NP) stage of the treatment pathway. The duration of pre-existing PNP was recorded.

\section{Treatment}

Study medication was prescribed in routine clinical practice. At each treatment visit, the size and location of the patient's painful area was assessed to determine the required area of treatment. Each capsaicin $8 \%$ patch contained $179 \mathrm{mg}$ of capsaicin $\left(640 \mu \mathrm{g}\right.$ per $\left.1 \mathrm{~cm}^{2}\right)$ and up to four patches were allowed per treatment. Multiple treatment areas were possible; the recommended treatment time was $30 \mathrm{~min}$ for the foot and $60 \mathrm{~min}$ for other anatomical sites. Patients were followed up by phone or during clinic visits (Fig. 1). Scheduled follow-up contact 


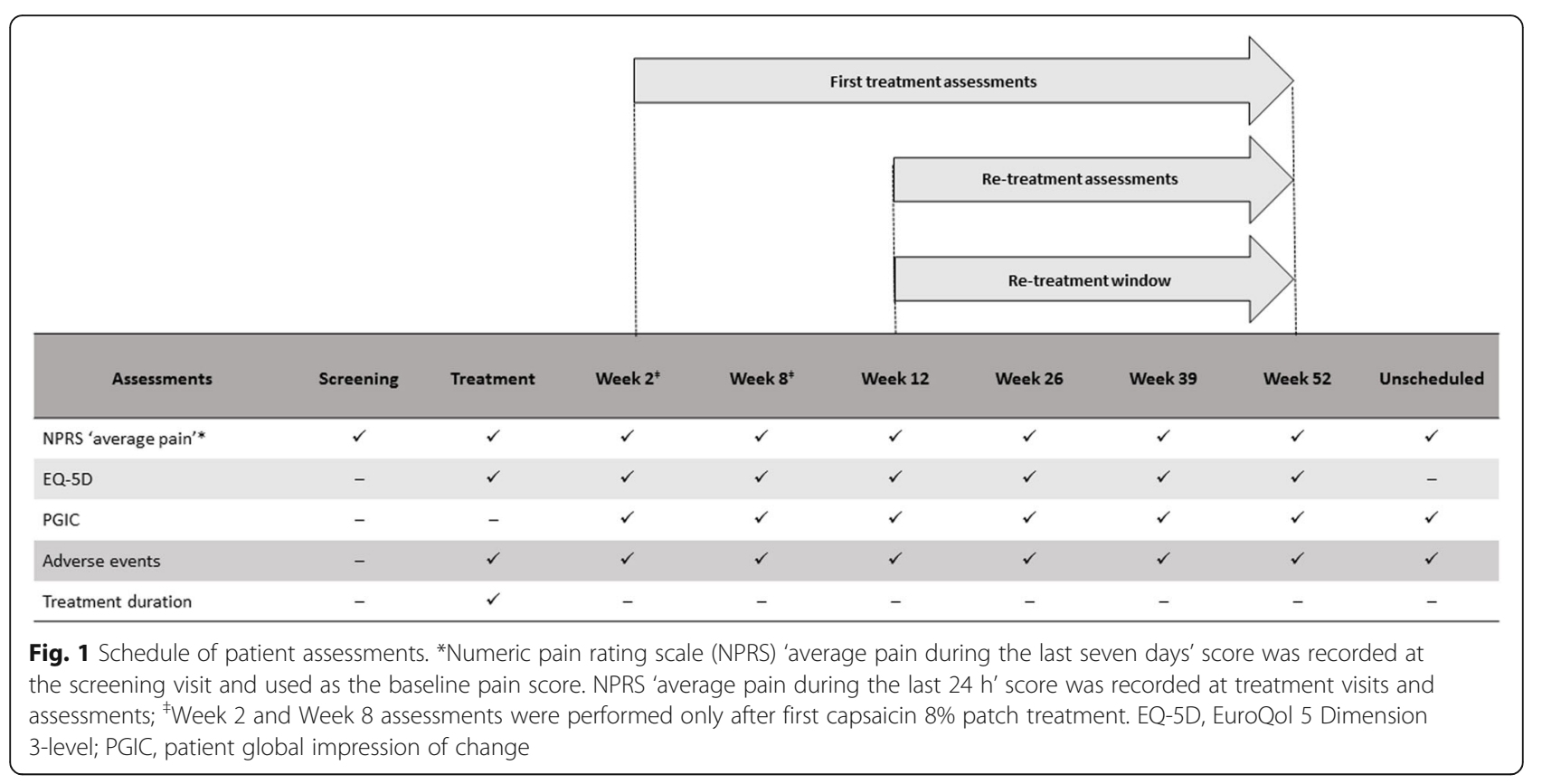

at Week 2 and Week 8 was made after first treatment only. Subsequent follow-up contact was made at Week 12, Week 26, Week 39 and Week 52. Multiple treatments with the capsaicin $8 \%$ patch were allowed, although intervals of at least 90 days between each application were recommended, consistent with the summary of product characteristics [20].

\section{Efficacy and tolerability assessments}

Patients assessed the intensity of their pain using an 11point numeric pain rating scale (NPRS) ranging from 0 (no pain) to 10 (worst imaginable pain) [21]. NPRS 'average pain during the last seven days' score was recorded at the screening visit and used as baseline pain in all related analyses. NPRS 'average pain during the last $24 \mathrm{~h}$ ' score was recorded at each treatment visit/assessment (prior to patch application). Sensitivity analysis was performed to exclude the effect of treatment outside of the recommended application time $(<90 \%$ and $\geq 110 \%)$ on the pain response. HRQoL was assessed using the EuroQol 5 Dimension 3-level (EQ-5D) questionnaire [22]. The default York MVH A1 value set [23] was used to derive the EQ-5D index for all observations in this study. The change in patients' general state of health was assessed by the patient global impression of change (PGIC) instrument [24] using a 7-point Likert scale, ranging from 1 (very much improved) to 7 (very much worse). Patients were asked to indicate how they felt 'now', compared with how they felt before receiving their most recent capsaicin $8 \%$ patch treatment.

The primary endpoints were: (i) the percentage change in mean NPRS 'average pain' score from baseline to the average of Weeks 2 and 8 following first capsaicin $8 \%$ patch treatment; and (ii) the median time between the first and second capsaicin $8 \%$ patch treatments. Secondary endpoints were: the percentage change in mean NPRS score from baseline to the average of Weeks 2 and 12 following re-treatment(s); the proportion of patients with a $\geq 30 \%$ or $\geq 50 \%$ reduction in mean NPRS score from baseline to the average of Weeks 2 and 8 for first treatment or the average of Weeks 2 and 12 for re-treatment (defined as $\geq 30 \%$ responders and $\geq 50 \%$ responders, respectively); the percentage change in mean NPRS scores from baseline to each assessment; median time between second and third treatment; number of capsaicin $8 \%$ patches used at each treatment; treatment area size at each treatment; the proportion of patients completing $\geq 90 \%$ of the recommended treatment duration at each application ( $\geq 27 \mathrm{~min}$ for the feet or $\geq 54$ min for all other anatomical sites); change in EQ-5D index from baseline to each assessment; proportion of patients with improved overall health status versus baseline according to the PGIC (i.e. very much improved, much improved or slightly improved) at assessments; proportion of patients reporting adverse events (AEs) and serious AEs (SAEs). All study assessments were performed at scheduled follow-up visits and, with the exception of EQ-5D, at additional, unscheduled visits.

\section{Statistical analyses}

All analyses were performed using the full analysis set (FAS), consisting of all patients who received treatment with the capsaicin $8 \%$ patch. The planned primary analysis was to test equivalence between the PHN group 
and each of the other PNP aetiology groups for each coprimary endpoint. The margin of equivalence for percentage change in mean NPRS score was set at $\pm 16 \%$ (comparable to a one-point change on the NPRS scale [25]) while for time to re-treatment, it was set at \pm 1 month according to clinical judgement. The decision to perform inferential equivalence testing between the patients in the PHN aetiology group and those in any of the other PNP aetiology groups for the analysis of the co-primary endpoints was based on the number of PHN patients recruited and the minimum number of patients in any one of the other aetiologies required to achieve $80 \%$ power.

Based on the actual number of PHN patients $(n=89)$, for the first co-primary endpoint (percentage change in mean NPRS score from baseline), recruitment in three of the aetiology groups (NBP, PONP and 'other') was sufficient to achieve $80 \%$ power. However, recruitment to the CRNP and HIV-AN aetiology groups fell below the minimum threshold; therefore comparison of neither group versus PHN was performed for this co-primary endpoint. An analysis of covariance was used to adjust for gender, country and baseline 'average pain' as fixedeffects covariates. Least squares mean estimates were provided with $95 \%$ confidence intervals (CIs). For the second co-primary endpoint (time to re-treatment), recruitment in all PNP aetiology groups fell below the minimum threshold to achieve sufficient power for testing equivalence. Therefore only descriptive time to event statistics derived using the Kaplan-Meier method were provided for each PNP aetiology group. Missing values were presented without imputation for all analyses. A sensitivity analysis was conducted in order to demonstrate consistency with the primary endpoint. Patients treated outside of the recommended application time $(<90 \%$ [ $<27 \mathrm{~min}$ for the feet; $<54 \mathrm{~min}$ for all other anatomical sites] and $\geq 110 \%$ [ $\geq 33 \mathrm{~min}$ for the feet; $\geq 66 \mathrm{~min}$ for all other anatomical sites]) were excluded from this analysis.

\section{Results}

\section{Patient characteristics}

A total of 429 patents were enrolled in the study and 420 patients received at least one treatment with the capsaicin $8 \%$ patch (FAS). Patients were from seven European countries: Austria (7 sites, $n=65)$, Greece (11 sites, $n=88$ ), Italy (8 sites, $n=30$ ), Portugal (11 sites, $n=98$ ), Spain (7 sites, $n=68$ ), Switzerland (2 sites, $n=$ 22 ) and United Kingdom (5 sites, $n=49$ ). The median age of the study population was 61 (range 21-98) years; $39.8 \%$ of patients were male; and the most common diagnoses were PONP $(47.1 \%, n=198)$ and PHN $(21.1 \%$, $n=89$ ) (Table 1). The proportion of patients in the primary, secondary or tertiary stage of the treatment pathway was $19.3 \%, 42.9 \%$ and $37.9 \%$, respectively. Overall, patients had a median follow-up time of 370 days (interquartile range: $360-434)$.

\section{Treatment exposure}

At first treatment, the mean number of patches used was 1.5 (standard deviation $[\mathrm{SD}] \pm 0.7$ ) and the mean treatment area was $306.4(\mathrm{SD} \pm 228.2) \mathrm{cm}^{2}$; both values remained consistent through successive applications (Table 2). A total of 239 (56.9\%) patients received only one treatment with the capsaicin $8 \%$ patch, 181 (43.1\%) patients received at least two treatments and $70(16.7 \%)$ patients received at least three treatments. At first treatment, patches were applied to the following body areas: legs $(36.2 \%, n=152)$; torso $(35.0 \%, n=147)$; feet $(16.2 \%$, $n=68)$; hands $(8.6 \%, n=36)$; arms $(8.3 \%, n=35)$; and the head and neck $(5.5 \%, n=23)$, excluding areas above the hairline of the scalp and/or in proximity to mucous membranes. During first treatment, 388 patients (92.4\%) completed $\geq 90 \%$ of the recommended duration of patch application. Similarly, 157 (94.0\%) and 63 (98.4\%) patients completed $\geq 90 \%$ of the recommended duration of patch application at second and third treatment, respectively.

\section{Pain scores}

Following first treatment with the capsaicin $8 \%$ patch, there was an overall $26.6 \%$ (95\% CI: $23.6,29.6 ; n=412$ ) reduction in mean NPRS 'average pain' score from baseline to Weeks 2 and 8 (co-primary endpoint) (Table 3; Fig. 2a). The findings of the sensitivity analysis were consistent with this result $(-27.7 \% ; n=254)$. The primary analysis demonstrated equivalence between the PHN group and each of NBP, PONP and 'other' groups as the difference did not exceed the pre-defined margin of equivalence (Fig. 2a). Patients who received second and third treatments had similar reductions in their mean NPRS scores of $28.7 \%$ (95\% CI: 22.9, 34.5; $n=161$ ) and $27.3 \%$ (95\% CI: 18.1, 36.5; $n=59$ ), respectively from baseline to Weeks 2 and 12. Overall, patients had a 24.5\% (95\% CI: 21.1, 27.9; $n=401$ ) reduction in their mean NPRS score from baseline to Week 2 and a 37.0\% (95\% CI: 31.3, 42.7; $n=176)$ reduction to Week 52 (Fig. 2b).

A total of $44.4 \%(n=183)$ and $26.2 \%(n=108)$ of patients were classified as $\geq 30 \%$ and $\geq 50 \%$ responders, respectively, after first treatment (Table 4). Of responders at Week 8, 86.9\% $(n=159 / 183)$ retained responder status at Week 12 after first treatment. There was a small increase in the percentage of responders following re-treatment. The percentage of $\geq 30 \%$ responders after second and third treatment was $49.1 \%(n=79)$ and $49.2 \%(n=29)$, respectively (Table 4$)$. The percentage of $\geq 50 \%$ responders at second and third treatment was 
Table 1 Patient demographics and baseline characteristics (FAS)

\begin{tabular}{|c|c|c|c|c|c|c|c|}
\hline & $\begin{array}{l}\text { PHN } \\
(n=89)\end{array}$ & $\begin{array}{l}\text { HIV-AN } \\
(n=5)\end{array}$ & $\begin{array}{l}\text { NBP } \\
(n=50)\end{array}$ & $\begin{array}{l}\text { CRNP } \\
(n=22)\end{array}$ & $\begin{array}{l}\text { PONP } \\
(n=198)\end{array}$ & $\begin{array}{l}\text { Other } \\
(n=56)\end{array}$ & $\begin{array}{l}\text { Overall } \\
(n=420)\end{array}$ \\
\hline \multicolumn{8}{|l|}{ Gender, $n(\%)$} \\
\hline Male & $36(40.4)$ & $5(100)$ & $17(34.0)$ & $5(22.7)$ & $75(37.9)$ & $29(51.8)$ & $167(39.8)$ \\
\hline Female & $53(59.6)$ & 0 & $33(66.0)$ & $17(77.3)$ & $123(62.1)$ & $27(48.2)$ & $253(60.2)$ \\
\hline \multicolumn{8}{|l|}{ Ethnicity, $n(\%)$} \\
\hline Caucasian & $88(98.9)$ & $4(80.0)$ & $49(98.0)$ & $19(86.3)$ & $185(93.4)$ & $55(98.2)$ & $400(95.2)$ \\
\hline Asian & 0 & $1(20.0)$ & 0 & 0 & $2(1.0)$ & 0 & $3(0.7)$ \\
\hline Black/African/Caribbean & $1(1.1)$ & 0 & $1(2.0)$ & $1(4.5)$ & $8(4.0)$ & $1(1.8)$ & $12(2.9)$ \\
\hline Mixed/multiple ethnic groups & 0 & 0 & 0 & $1(4.5)$ & $1(0.5)$ & 0 & $2(0.5)$ \\
\hline Not recorded & 0 & 0 & 0 & $1(4.5)$ & $2(1.0)$ & 0 & $3(0.7)$ \\
\hline Median age, years (min-max) & 72 (37-98) & $52(33-59)$ & $63(27-90)$ & $59(42-76)$ & $54(21-83)$ & $60(24-86)$ & $61(21-98)$ \\
\hline Median duration of pain, years (min-max) & $1.0(0.1-73.2)$ & $0.3(0.2-13.6)$ & $2.6(0-40.0)$ & $2.2(0.2-8.1)$ & $2.6(0.1-50.1)$ & $2.2(0.1-29.2)$ & $2.1(0-73.2)$ \\
\hline \multicolumn{8}{|l|}{ Treatment pathway, $n$ (\%) } \\
\hline Primary & $13(14.6)$ & $1(20.0)$ & $20(40.0)$ & $2(9.1)$ & $35(17.7)$ & $10(17.9)$ & $81(19.3)$ \\
\hline Secondary & $48(53.9)$ & $3(60.0)$ & $14(28.0)$ & $13(59.1)$ & 78 (39.4) & $24(42.9)$ & $180(42.9)$ \\
\hline Tertiary & $28(31.5)$ & $1(20.0)$ & $16(32.0)$ & $7(31.8)$ & $85(42.9)$ & $22(39.3)$ & $159(37.9)$ \\
\hline Baseline 'average pain', $n$ (SD) & $7.1(2.0)$ & $6.4(1.5)$ & $7.3(2.0)$ & $7.2(1.5)$ & $6.8(1.8)$ & $6.9(1.8)$ & $6.9(1.8)$ \\
\hline $\begin{array}{l}\text { Mean number of concomitant medications, } \\
n(S D)\end{array}$ & $1.8(1.5)$ & $1.4(1.5)$ & 1.5 (1.6) & $2.2(1.4)$ & $1.9(1.5)$ & 1.7 (1.4) & $1.8(1.5)$ \\
\hline
\end{tabular}

${ }^{a}$ Average pain during the 7 days prior to screening visit; ${ }^{b}$ Number of concomitant medications for neuropathic pain at screening visit. $C R N P$, cancer-related neuropathic pain; FAS, full analysis set; HIV-AN, HIV associated neuropathy; NBP, neuropathic back pain; NPRS, numeric pain rating scale; Other, other non-diabetic PNP; $P H N$, postherpetic neuralgia; PONP, post-operative and post-traumatic neuropathic pain; $S D$, standard deviation

$30.4 \%(n=49)$ and $30.5 \%(n=18)$, respectively. These findings suggest that the proportion of responders was maintained with each subsequent capsaicin $8 \%$ patch treatment.

In a subgroup analysis, patients in the shortest PNP duration quartile of $0-0.72$ years had a $36.3 \%$ (95\% CI: $30.0,42.6 ; n=101$ ) reduction in their mean NPRS score from baseline to Weeks 2 and 8 compared with reductions of $23.6 \%$ (95\% CI: 17.1, 30.1; $n=104)$, $25.0 \%$ (95\% CI: $19.4,30.6 ; n=104)$, and $21.8 \%(95 \%$ CI: $16.4,27.2 ; n=103)$, in the $0.72-2.1$ years, $>2.1-$ 5.4 years and $>5.4$ years quartiles, respectively. Similarly, $62.4 \%$ of patients in the shortest PNP duration quartile ( $0-0.72$ years) were $\geq 30 \%$ responders after first treatment, followed by $39.4 \%$ of patients in 0.72 2.1 years, $40.4 \%$ in $>2.1-5.4$ years, and $35.9 \%$ in $>5.4$ years PNP duration quartiles, respectively. In patients classified as being in the primary, secondary and tertiary stages of the treatment pathway, the change in mean NPRS scores from baseline to Weeks 2 and 8 was $-30.5 \%(n=80),-28.1 \%(n=177)$, and $-22.8 \%(n=155)$, respectively.

\section{Time to re-treatment}

Patients had a median time from first to second treatment of 191 days (95\% CI: 147, 235; $n=181$ ) (co-primary endpoint) and a median time from second to third treatment of 301 days (95\% CI: 245, 357; $n=70$ ) (Fig. 3a). The median time to second treatment for the PHN and PONP groups was 180 days (95\% CI: 116,$244 ; n=40$ ) and 161 days (95\% CI: 120,$202 ; n=97$ ), respectively (Fig. 3b). Median time to second treatment could not be calculated for NBP and the 'other' aetiology groups within the period of the study and the HIV-AN and CRNP aetiology groups were excluded due to low recruitment.

\section{EQ-5D}

The mean EQ-5D health state utility score increased by 0.199 utils at Week 2 (from a baseline score of 0.345 utils), at least two-times greater than the minimally important difference of 0.074 utils [26]. This improvement was maintained to Week 52 following first treatment (Table 5). Responders to capsaicin $8 \%$ patch treatment reported the most substantial improvements in HRQoL. At Week 2 after first treatment, $\geq 30 \%$ and $\geq 50 \%$ responders had increases of 0.292 utils and 0.327 utils, respectively in their EQ5D scores from baseline.

PGIC

Analysis of PGIC demonstrated that the majority of patients experienced an improvement (very much, much or slightly) in health status during the study (Table 6). 
Table 2 Treatment exposure (FAS)

\begin{tabular}{|c|c|c|c|c|c|c|c|}
\hline & $\begin{array}{l}\text { PHN } \\
(n=89)\end{array}$ & $\begin{array}{l}\text { HIV-AN } \\
(n=5)\end{array}$ & $\begin{array}{l}\text { NBP } \\
(n=50)\end{array}$ & $\begin{array}{l}\text { CRNP } \\
(n=22)\end{array}$ & $\begin{array}{l}\text { PONP } \\
(n=198)\end{array}$ & $\begin{array}{l}\text { Other } \\
(n=56)\end{array}$ & $\begin{array}{l}\text { Overall } \\
(n=420)\end{array}$ \\
\hline \multicolumn{8}{|c|}{ Patients treated at each application, $n(\%)$} \\
\hline First treatment & $89(21.2)$ & $5(1.2)$ & $50(11.9)$ & $22(5.2)$ & $198(47.1)$ & $56(13.3)$ & $420(100)$ \\
\hline Second treatment & $40(9.5)$ & $2(0.5)$ & $15(3.6)$ & $8(1.9)$ & $97(23.1)$ & $19(4.5)$ & $181(43.1)$ \\
\hline Third treatment & $16(3.8)$ & - & $4(1.0)$ & $4(1.0)$ & $38(9.0)$ & $8(1.9)$ & $70(16.7)$ \\
\hline \multicolumn{8}{|c|}{ Mean size of treatment area, $\mathrm{cm}^{2}(\mathrm{SD})$} \\
\hline First treatment & $298.6(168.1)$ & $380.0(138.6)$ & $297.7(196.9)$ & $519.5(404.9)$ & $271.5(209.7)$ & $362.0(263.9)$ & $306.4(228.2)$ \\
\hline Second treatment & $286.8(169.3)$ & $210.0(99.0)$ & $291.3(160.6)$ & $566.6(387.9)$ & $278.6(206.4)$ & $391.5(300.5)$ & $306.4(225.0)$ \\
\hline Third treatment & $270.0(190.6)$ & - & $357.5(230.7)$ & $467.5(113.5)$ & $229.7(211.8)$ & $487.4(412.4)$ & $294.8(248.8)$ \\
\hline \multicolumn{8}{|c|}{ Mean number of patches (SD) } \\
\hline First treatment & $1.4(0.6)$ & $1.4(0.6)$ & $1.3(0.6)$ & $2.1(1.3)$ & $1.4(0.7)$ & $1.6(0.8)$ & $1.5(0.7)$ \\
\hline Second treatment & $1.4(0.6)$ & $1.0(0.0)$ & $1.4(0.6)$ & $2.3(1.2)$ & $1.5(0.7)$ & $1.7(0.9)$ & $1.5(0.7)$ \\
\hline Third treatment & $1.4(0.7)$ & - & $1.8(1.0)$ & $2.0(0.0)$ & $1.4(0.8)$ & $2.0(1.3)$ & $1.6(0.8)$ \\
\hline \multicolumn{8}{|c|}{ Patients completing $\geq 90 \%$ of recommended treatment duration ${ }^{\mathrm{a}}, n(\%)$} \\
\hline First treatment & $84(94.4)$ & $5(100)$ & $47(94.0)$ & $19(86.4)$ & $184(93.9)$ & 49 (87.5) & $388(92.8)$ \\
\hline Second treatment & 37 (94.9) & $2(100)$ & $12(85.7)$ & $7(87.5)$ & $81(94.2)$ & $18(100)$ & $157(94.0)$ \\
\hline Third treatment & $16(100)$ & - & $4(100)$ & $4(100)$ & $33(100)$ & $7(87.5)$ & 63 (98.4) \\
\hline
\end{tabular}

${ }^{\mathrm{a}}$ Recommended treatment duration times were $30 \mathrm{~min}$ for foot and $60 \mathrm{~min}$ for other anatomical locations. For patients treated on the foot, the treatment time corresponding to the percentage duration was $27-33 \mathrm{~min}$ for $\geq 90 \%$ to $<110 \%$ and $>33 \mathrm{~min}$ for $\geq 110 \%$. For patients treated on other locations, the treatment time corresponding to the percentage duration was $54-66$ min for $\geq 90 \%$ to $<110 \%$ and $>66$ min for $\geq 110 \%$. CRNP, cancer-related neuropathic pain; FAS, full analysis set; HIV-AN, HIV associated neuropathy; NPRS, numeric pain rating scale; PHN, postherpetic neuralgia; NBP, neuropathic back pain; Other, other non-diabetic PNP; $P O N P$, post-operative and post-traumatic neuropathic pain; $S D$, standard deviation

Table 3 NPRS 'average pain' scores at baseline and Weeks 2 and 8 (FAS)

\begin{tabular}{|c|c|c|c|c|c|c|c|}
\hline NPRS 'average pain' scores & $\begin{array}{l}\text { PHN } \\
(n=89)\end{array}$ & $\begin{array}{l}\text { HIV-AN } \\
(n=5)\end{array}$ & $\begin{array}{l}\text { NBP } \\
(n=50)\end{array}$ & $\begin{array}{l}\text { CRNP } \\
(n=22)\end{array}$ & $\begin{array}{l}\text { PONP } \\
(n=198)\end{array}$ & $\begin{array}{l}\text { Other } \\
(n=56)\end{array}$ & $\begin{array}{l}\text { Overall } \\
(n=420)\end{array}$ \\
\hline \multicolumn{8}{|l|}{ First treatment } \\
\hline Baseline, mean (95\% Cl) & $\begin{array}{l}7.1(6.9,7.5) \\
n=88\end{array}$ & $\begin{array}{l}6.4(5.1,7.7) \\
n=5\end{array}$ & $\begin{array}{l}7.3(6.8,7.9) \\
n=50\end{array}$ & $\begin{array}{l}7.2(6.6,7.8) \\
n=22\end{array}$ & $\begin{array}{l}6.8(6.6,7.1) \\
n=198\end{array}$ & $\begin{array}{l}6.9(6.4,7.4) \\
n=56\end{array}$ & $\begin{array}{l}6.9(6.7,7.1) \\
n=419\end{array}$ \\
\hline $\begin{array}{l}\text { Weeks } 2 \text { and } 8 \text {, mean } \\
(95 \% \mathrm{Cl})\end{array}$ & $\begin{array}{l}4.9(4.4,5.4) \\
n=89\end{array}$ & $\begin{array}{l}4.6(2.0,7.3) \\
n=4\end{array}$ & $\begin{array}{l}4.8(4.2,5.5) \\
n=48\end{array}$ & $\begin{array}{l}5.8(4.9,6.7) \\
n=21\end{array}$ & $\begin{array}{l}5.2(4.9,5.5) \\
n=195\end{array}$ & $\begin{array}{l}4.5(4.0,5.1) \\
n=56\end{array}$ & $\begin{array}{l}5.0(4.8,5.2) \\
n=412\end{array}$ \\
\hline $\begin{array}{l}\text { Percentage reduction, } \\
\text { mean }(95 \% \mathrm{Cl})\end{array}$ & $29.7(23.4,36.0)$ & $34.5(7.6,61.5)$ & $30.9(21.7,40.1)$ & $21.0(11.6,30.5)$ & $22.3(17.7,27.0)$ & $34.3(27.3,41.4)$ & $26.6(23.6,29.6)$ \\
\hline \multicolumn{8}{|l|}{ Second treatment } \\
\hline Baseline, mean (95\% Cl) & $\begin{array}{l}7.1(6.5,7.7) \\
n=39\end{array}$ & $\begin{array}{l}6.5(3.6,9.4) \\
n=2\end{array}$ & $\begin{array}{l}7.7(6.7,8.7) \\
n=15\end{array}$ & $\begin{array}{l}6.9(5.9,7.9) \\
n=8\end{array}$ & $\begin{array}{l}6.8(6.4,7.2) \\
n=97\end{array}$ & $\begin{array}{l}6.6(5.7,7.5) \\
n=19\end{array}$ & $\begin{array}{l}6.9(6.6,7.2) \\
n=180\end{array}$ \\
\hline $\begin{array}{l}\text { Weeks } 2 \text { and 12, mean } \\
(95 \% \mathrm{Cl})\end{array}$ & $\begin{array}{l}4.7(4.1,5.3) \\
n=39\end{array}$ & $\begin{array}{l}3(-) \\
n=2\end{array}$ & $\begin{array}{l}4.3(2.8,5.8) \\
n=12\end{array}$ & $\begin{array}{l}3.4(1.6,5.2) \\
n=6\end{array}$ & $\begin{array}{l}4.9(4.4,5.4) \\
n=85\end{array}$ & $\begin{array}{l}5.1(4.1,6.1) \\
n=18\end{array}$ & $\begin{array}{l}4.8(4.5,5.1) \\
n=162\end{array}$ \\
\hline $\begin{array}{l}\text { Percentage reduction, } \\
\text { mean }(95 \% \mathrm{Cl})\end{array}$ & $\begin{array}{l}30.5(19.8,41.2) \\
n=38\end{array}$ & $\begin{array}{l}51.3(29.2,73.4) \\
n=2\end{array}$ & $\begin{array}{l}44.9(24.7,65.1) \\
n=12\end{array}$ & $\begin{array}{l}51.0(24.3,77.7) \\
n=6\end{array}$ & $\begin{array}{l}25.0(16.5,33.5) \\
n=85\end{array}$ & $\begin{array}{l}21.4(5.2,37.6) \\
n=18\end{array}$ & $\begin{array}{l}28.7(22.9,34.5) \\
n=161\end{array}$ \\
\hline \multicolumn{8}{|l|}{ Third treatment } \\
\hline Baseline, mean (95\% Cl) & $\begin{array}{l}6.9(5.9,7.9) \\
n=16\end{array}$ & - & $\begin{array}{l}7.5(4.6,10.4) \\
n=4\end{array}$ & $\begin{array}{l}7.8(6.3,9.3) \\
n=4\end{array}$ & $\begin{array}{l}6.3(5.8,6.8) \\
n=38\end{array}$ & $\begin{array}{l}6.8(5.6,8.0) \\
n=8\end{array}$ & $\begin{array}{l}6.7(6.3,7.1) \\
n=70\end{array}$ \\
\hline $\begin{array}{l}\text { Weeks } 2 \text { and 12, mean } \\
(95 \% \mathrm{Cl})\end{array}$ & $\begin{array}{l}3.9(2.9,4.9) \\
n=14\end{array}$ & - & $\begin{array}{l}5.5(3.5,7.5) \\
n=4\end{array}$ & $\begin{array}{l}5.0(2.6,7.4) \\
n=4\end{array}$ & $\begin{array}{l}4.4(3.7,5.1) \\
n=29\end{array}$ & $\begin{array}{l}5.2(4.2,6.2) \\
n=8\end{array}$ & $\begin{array}{l}4.5(4.0,5.0) \\
n=59\end{array}$ \\
\hline $\begin{array}{l}\text { Percentage reduction, } \\
\text { mean }(95 \% \mathrm{Cl})\end{array}$ & $\begin{array}{l}42.3(26.8,57.8) \\
n=14\end{array}$ & - & $\begin{array}{l}25.4(15.3,35.5) \\
n=4\end{array}$ & $\begin{array}{l}35.5(8.8,62.2) \\
n=4\end{array}$ & $\begin{array}{l}23.1(9.5,36.7) \\
n=29\end{array}$ & $\begin{array}{l}13.6(-20.8,48.0) \\
n=8\end{array}$ & $\begin{array}{l}27.3(18.1,36.5) \\
n=59\end{array}$ \\
\hline
\end{tabular}

$C l$, confidence interval; $C R N P$, cancer-related neuropathic pain; $F A S$, full analysis set; HIV-AN, HIV associated neuropathy; NBP, neuropathic back pain; $N P R S$, numeric pain rating scale; Other, other non-diabetic PNP; $P H N$, postherpetic neuralgia; $P O N P$, post-operative and post-traumatic neuropathic pain 


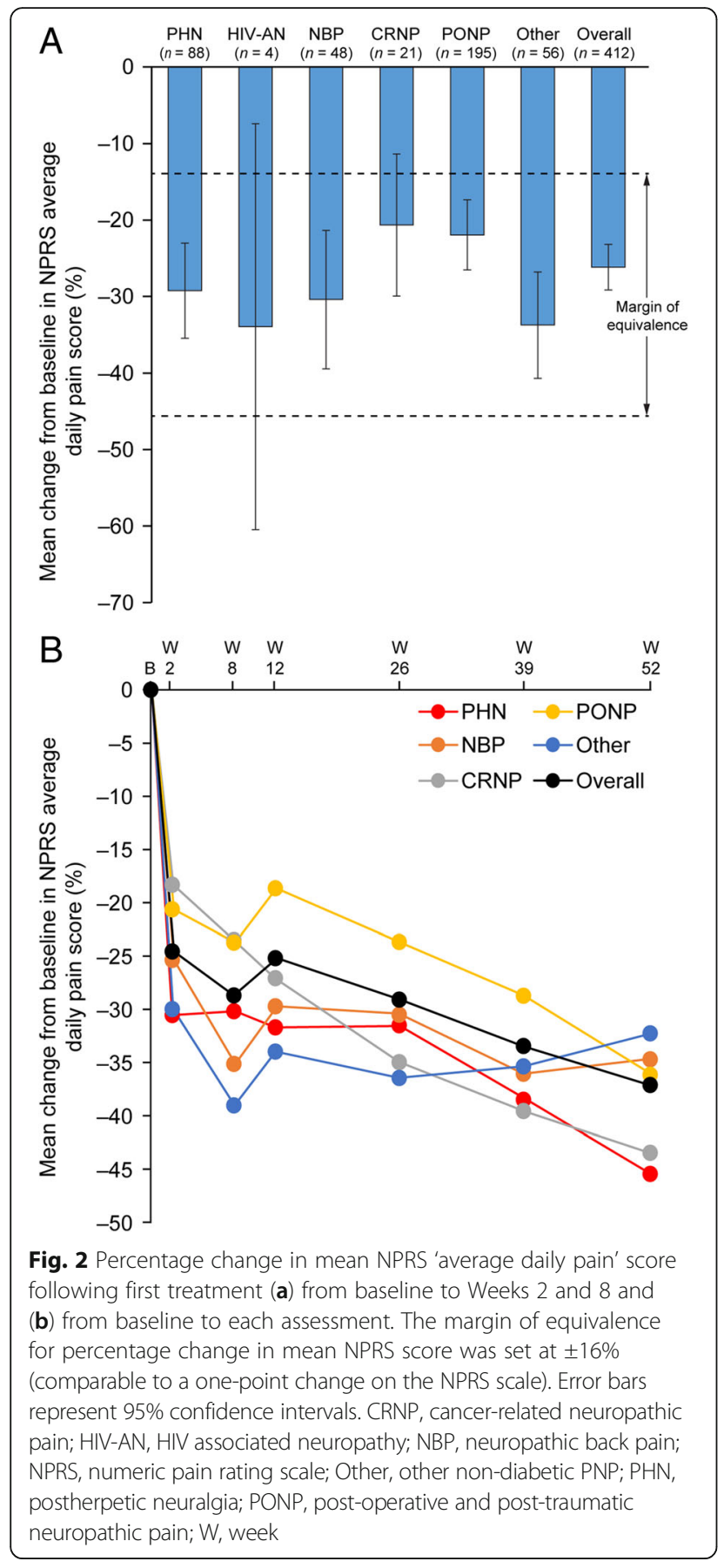

Following first, second and third treatment applications, $61.0 \% \quad(n=224 / 367), 74.6 \% \quad(n=112 / 150)$ and $78.7 \%(n=37 / 47)$ of patients, respectively reported improved status at Week 12 , while $7.4 \%(n=27 / 367)$, $5.3 \% \quad(n=8 / 150)$ and $4.3 \% \quad(n=2 / 47)$ of patients reported some deterioration. At Week 52, following first, second or third treatment, more than half of all patients had an improvement in PGIC and less than $8 \%$ had worsened.
Table 4 Responders after each capsaicin 8\% patch treatment

\begin{tabular}{ll}
\hline NPRS 'average pain' score reduction & Responders, $n(\%)$ \\
\hline First treatment $(n=412)$ & \\
$\geq 30 \%$ reduction from baseline to Weeks 2 and 8 & $183(44.4)$ \\
$\geq 50 \%$ reduction from baseline to Weeks 2 and 8 & $108(26.2)$ \\
Second treatment $(n=161)$ & \\
$\geq 30 \%$ reduction from baseline to Weeks 2 and 12 & $79(49.1)$ \\
$\geq 50 \%$ reduction from baseline to Weeks 2 and 12 & $49(30.4)$ \\
Third treatment $(n=59)$ & \\
$\geq 30 \%$ reduction from baseline to Weeks 2 and 12 & $29(49.2)$ \\
$\geq 50 \%$ reduction from baseline to Weeks 2 and 12 & $18(30.5)$ \\
\hline
\end{tabular}

NPRS numeric pain rating scale

\section{Tolerability}

Capsaicin $8 \%$ patch treatment was generally well tolerated. Over the course of the study, $47(11.2 \%)$ patients reported a total of 91 AEs. The number of patients reporting at least one $\mathrm{AE}$ following first, second, third and fourth treatment was 26 (6.2\%), 15 (3.6\%), 5 (1.2\%) and $1(0.2 \%)$, respectively. The most frequently reported AEs were anticipated capsaicin-related application site reactions (8.3\%; $n=35)$ including erythema (8.1\%; $n=34)$, pain $(5.0 \% ; n=21)$ and pruritus $(1.0 \% ; n=4)$. Twenty-one SAEs were reported in 9 (2.1\%) patients; five of these reported for one patient were probably treatment-related (two application site erythema, two application site pruritus and one headache). Four patients died during the study; causes of death were assessed by the treating physicians and were not considered to be treatment-related.

\section{Discussion}

ASCEND was the first real-world study to demonstrate that treatment with the capsaicin $8 \%$ patch can provide effective, rapid and sustained pain relief in a heterogeneous population with respect to PNP aetiologies, gender, age, and duration of previous neuropathic pain. A pain response was observed as early as Week 2, in common with previous clinical studies $[12,16,18]$. Long-term follow up of patients enabled the observation that the median time to second treatment was more than 26 weeks and increased to over 43 weeks from second to third treatment. There were also clear benefits in HRQoL and in treating patients with a short history of PNP. In line with other analgesics such as pregabalin and gabapentin $[27,28]$, observations of the capsaicin $8 \%$ patch in routine clinical practice were consistent with findings from clinical trials [12-16].

The mean NPRS 'average pain' reduction from baseline to Weeks 2 and 8 (26.6\%), and to Weeks 2 and 12 after second and third treatment (28.7\% and $27.3 \%)$, was consistent with Phase 3 studies of the capsaicin $8 \%$ patch 

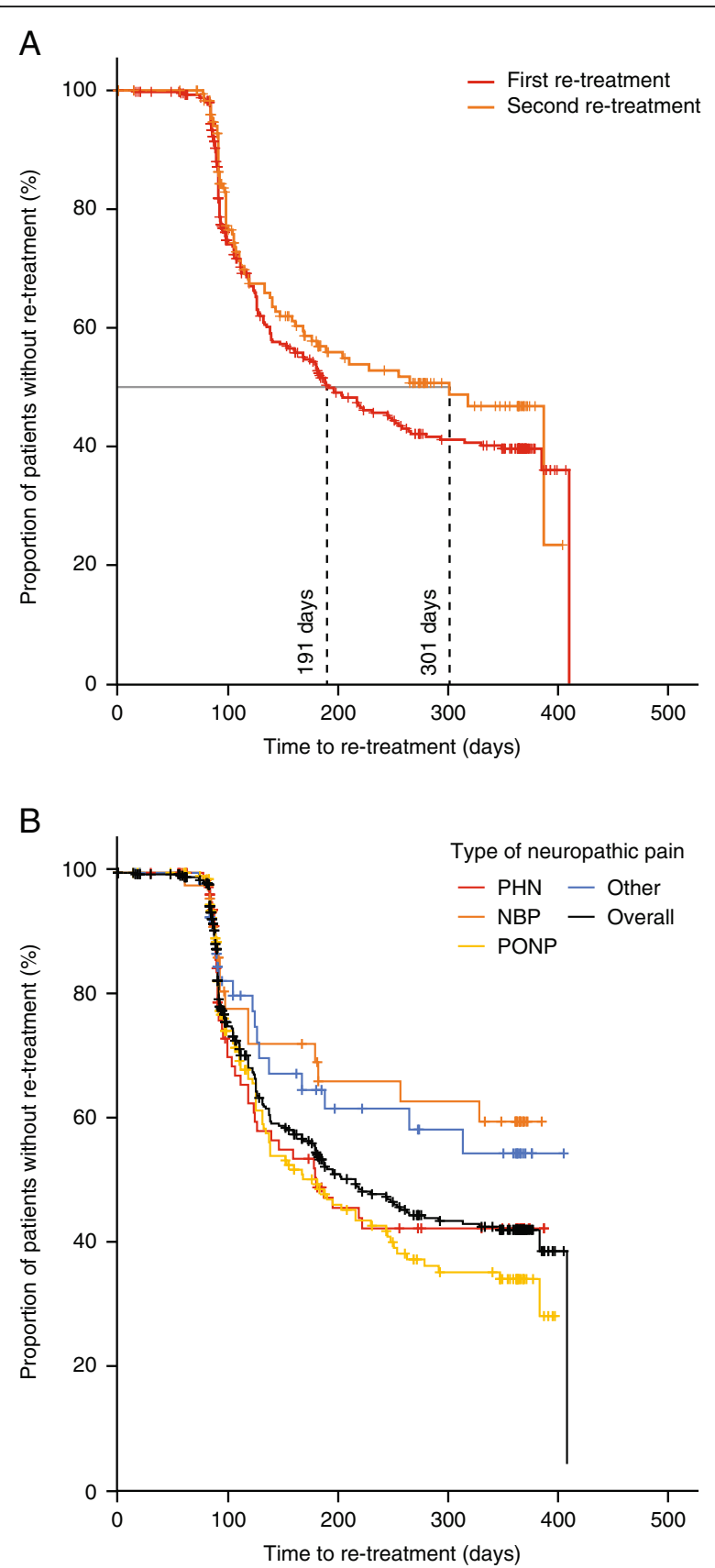

Fig. 3 Capsaicin 8\% patch re-treatment intervals between (a) first and second treatment and second and third treatment; and (b) time between first and second treatment by aetiology group. NBP, neuropathic back pain; Other, other non-diabetic PNP; PHN, postherpetic neuralgia; PONP, post-operative and post-traumatic neuropathic pain

in non-diabetic patients with PHN $[12,14]$ and HIV-AN $[13,16]$. These findings are further supported by a randomised, open-label, non-inferiority study of the capsaicin $8 \%$ patch versus pregabalin (ELEVATE study) where non-diabetic patients with PHN, peripheral nerve injury or non-diabetic painful peripheral polyneuropathy had non-inferior pain relief versus pregabalin treatment, with a more rapid onset of action, fewer systemic effects and greater patient satisfaction with treatment [18]. In addition, studies performed in parallel to the ASCEND study have reported positive data for capsaicin $8 \%$ patch treatment in patients with painful diabetic peripheral neuropathy $[29,30]$. A recent European label extension now allows for the use of the capsaicin $8 \%$ patch, either alone or in combination with other pain medications, in adults with diabetic PNP. Together, these data confirm that the capsaicin $8 \%$ patch provides consistent pain relief in a broad range of PNP aetiologies.

A potential advantage of the capsaicin $8 \%$ patch over other treatments is that a single treatment can provide lasting pain relief. In this study, almost half of all patients achieved a clinically important $\geq 30 \%$ reduction [21] in mean NPRS 'average pain' by Weeks 2 and 8 following first treatment, which was sustained in patients receiving re-treatment. Significantly, $86.9 \%$ of $\geq 30 \%$ responders at Weeks 2 and 8 were also classified as responders at Week 12. These results are concordant with a study in patients with HIV-AN [31], where responders $(\geq 30 \%$ reduction in 'average pain' from baseline to Weeks 2 and 12) maintained a response for a median time of 17 weeks $(95 \%$ CI: 13, 27) after a single treatment with the capsaicin $8 \%$ patch. Taken together, these data support the conclusion that a clinically important pain response with capsaicin $8 \%$ patch treatment is likely to be sustained over time and with successive treatments.

PNP treatment guidelines suggest the use of the capsaicin $8 \%$ patch as second-line treatment for localised neuropathic pain [6]. The duration of pre-existing pain and the stage of the treatment pathway, in relation to capsaicin $8 \%$ patch treatment, were assessed in this study. Higher levels of pain reduction were observed in patients treated within the primary and secondary stages of the treatment pathway compared with the tertiary stages. Furthermore, the shortest PNP duration quartile (0-0.72 years) had the largest mean percentage reduction in pain intensity from baseline to Weeks 2 and 8 , and the highest percentage of responders $(\geq 30 \%$ reduction in mean NPRS score). This is consistent with findings from a 12-week non-interventional study (QUEPP), where patients with pre-existing pain of less than 6 months benefited to a greater extent than patients with a longer history of pain [19], indicating that the capsaicin $8 \%$ patch may be most effective in earlier stages of PNP treatment or after recent onset of neuropathic pain.

The number of capsaicin $8 \%$ patches used per treatment in this study (1.5 patches/treatment) was consistent with the ELEVATE study [18], but considerably lower than that observed in randomised studies (mean 
Table 5 EQ-5D index scores following first 8\% capsaicin patch treatment

\begin{tabular}{|c|c|c|c|c|c|}
\hline \multirow[t]{2}{*}{ EQ-5D index score } & \multicolumn{2}{|c|}{ Responders at Weeks 2 and 8} & \multicolumn{2}{|c|}{ Non-responders at Weeks 2 and 8} & \multirow[t]{2}{*}{ Overall } \\
\hline & $\geq 30 \%^{a}$ & $\geq 50 \%^{a}$ & $<30 \%^{\mathrm{a}}$ & $<50 \%^{a}$ & \\
\hline Baseline, mean (SD) & $\begin{array}{l}0.392(0.352) \\
n=182\end{array}$ & $\begin{array}{l}0.386(0.367) \\
n=108\end{array}$ & $\begin{array}{l}0.306(0.349) \\
n=229\end{array}$ & $\begin{array}{l}0.329(0.347) \\
n=303\end{array}$ & $\begin{array}{l}0.345(0.354) \\
n=419\end{array}$ \\
\hline \multicolumn{6}{|c|}{ Change from baseline, mean (SD) } \\
\hline Week 2 & $\begin{array}{l}0.292(0.313) \\
n=176\end{array}$ & $\begin{array}{l}0.337(0.327) \\
n=104\end{array}$ & $\begin{array}{l}0.128(0.297) \\
n=223\end{array}$ & $\begin{array}{l}0.152(0.296) \\
n=295\end{array}$ & $\begin{array}{l}0.199(0.315) \\
n=400\end{array}$ \\
\hline Week 8 & $\begin{array}{l}0.323(0.307) \\
n=165\end{array}$ & $\begin{array}{l}0.349(0.321) \\
n=99\end{array}$ & $\begin{array}{l}0.104(0.323) \\
n=209\end{array}$ & $\begin{array}{l}0.147(0.322) \\
n=275\end{array}$ & $\begin{array}{l}0.200(0.333) \\
n=375\end{array}$ \\
\hline Week 12 & $\begin{array}{l}0.289(0.352) \\
n=165\end{array}$ & $\begin{array}{l}0.342(0.359) \\
n=97\end{array}$ & $\begin{array}{l}0.111(0.320) \\
n=196\end{array}$ & $\begin{array}{l}0.138(0.325) \\
n=264\end{array}$ & $\begin{array}{l}0.190(0.348) \\
n=363\end{array}$ \\
\hline Week 26 & $\begin{array}{l}0.288(0.292) \\
n=93\end{array}$ & $\begin{array}{l}0.309(0.290) \\
n=62\end{array}$ & $\begin{array}{l}0.099(0.339) \\
n=112\end{array}$ & $\begin{array}{l}0.131(0.334) \\
n=143\end{array}$ & $\begin{array}{l}0.185(0.330) \\
n=206\end{array}$ \\
\hline Week 39 & $\begin{array}{l}0.306(0.320) \\
n=78\end{array}$ & $\begin{array}{l}0.310(0.321) \\
n=52\end{array}$ & $\begin{array}{l}0.123(0.335) \\
n=96\end{array}$ & $\begin{array}{l}0.161 \\
n=122\end{array}$ & $\begin{array}{l}0.205(0.340) \\
n=174\end{array}$ \\
\hline Week 52 & $\begin{array}{l}0.307(0.327) \\
n=76\end{array}$ & $\begin{array}{l}0.305(0.330) \\
n=52\end{array}$ & $\begin{array}{l}0.114(0.376) \\
n=100\end{array}$ & $\begin{array}{l}0.153(0.373) \\
n=124\end{array}$ & $\begin{array}{l}0.198(0.367) \\
n=176\end{array}$ \\
\hline
\end{tabular}

apercentage reduction in average NPRS score. EQ-5D, EuroQol 5 Dimension 3-level; SD, standard deviation

Table 6 Patient Global Impression of Change (PGIC) responses

\begin{tabular}{|c|c|c|c|}
\hline \multirow[t]{2}{*}{ Response } & \multicolumn{3}{|l|}{ Patients, n (\%) } \\
\hline & First treatment & Second treatment & Third treatment \\
\hline Week 2 & $n=408$ & & \\
\hline Improved & $258(63.2)$ & & \\
\hline No change & $117(28.7)$ & & \\
\hline Worsened & $33(8.1)$ & & \\
\hline Week 8 & $n=368$ & & \\
\hline Improved & $231(62.8)$ & & \\
\hline No change & $110(29.9)$ & & \\
\hline Worsened & $27(7.3)$ & & \\
\hline Week 12 & $n=367$ & $n=150$ & $n=47$ \\
\hline Improved & $224(61.0)$ & $112(74.7)$ & 37 (78.7) \\
\hline No change & 116 (31.6) & $30(20.0)$ & $8(17.0)$ \\
\hline Worsened & $27(7.4)$ & $8(5.3)$ & $2(4.3)$ \\
\hline Week 26 & $n=207$ & $n=101$ & $n=28$ \\
\hline Improved & $113(54.6)$ & $67(66.3)$ & $23(82.1)$ \\
\hline No change & $76(36.7)$ & $26(25.7)$ & $3(10.7)$ \\
\hline Worsened & $18(8.7)$ & $8(7.9)$ & $2(7.1)$ \\
\hline Week 39 & $n=177$ & $n=81$ & $n=21$ \\
\hline Improved & $96(54.2)$ & $50(61.7)$ & $18(85.7)$ \\
\hline No change & $65(36.7)$ & $24(29.6)$ & $1(4.8)$ \\
\hline Worsened & $16(9.0)$ & $7(8.6)$ & $2(9.5)$ \\
\hline Week 52 & $n=176$ & $n=56$ & $n=7$ \\
\hline Improved & $93(52.8)$ & $38(67.9)$ & $5(71.4)$ \\
\hline No change & $71(40.3)$ & $14(25.0)$ & $1(14.3)$ \\
\hline Worsened & $12(6.8)$ & $4(7.1)$ & $1(14.3)$ \\
\hline
\end{tabular}

Improved: slightly, much, very much; Worsened: slightly, much, very much
2.3 patches/treatment) [12, 14], despite comparable treatment area sizes. This may be related to differences in the number of patches per pack between the Phase 3 randomised controlled studies (4 patches/pack) and those used in routine clinical practice (1 patch/pack) or the cost of treatment in routine clinical practice versus a clinical trial. The lower number of patches used in this study did not affect the reported efficacy.

Patients with PNP can experience considerable impairment in HRQoL as highlighted by the EQ-5D index at baseline (0.345 utils), which suggests the typical UK adult would choose to forfeit almost two-thirds of their remaining lifespan in order to avoid this state of health [23]. The capsaicin 8\% patch improved HRQoL as demonstrated by an improvement in the EQ-5D index and PGIC. The improvement from baseline in the EQ-5D index at Week 2 (0.199 utils) was maintained up to the final measurement at Week 52. It was also observed that responders had the greatest improvements in EQ-5D. Furthermore, $61.0 \%$ of patients reported an improved health status at Week 12 as measured by PGIC, similar to results obtained from previous studies in patients with HIV-AN (67\%) and PHN (62\%) [13, 14]. This result was sustained over successive treatments and up to Week 52 (52.8\%).

The capsaicin $8 \%$ patch was shown to be well tolerated across a range of aetiologies with over $92 \%$ of patients completing at least $90 \%$ of the suggested patch application duration at first or subsequent treatments. Similarly, 98\% of patients in a previous study with PHN completed at least $90 \%$ of the suggested patch application duration [14]. AEs were reported for $11 \%$ of patients and most were anticipated application site reactions. The frequency of adverse events reported in other studies of the 
capsaicin 8\% patch was higher (98-99\%), but the majority were also application site reactions [12, 14]. Repeated use of the capsaicin $8 \%$ patch did not increase the frequency of AEs, supporting findings from an open-label study in patients with HIV-AN who had up to three applications [31].

The strengths of the ASCEND trial include a large and heterogeneous population, a real-world setting, inclusion of patients with different PNP aetiologies and the monitoring of patients for at least one year after treatment and over multiple treatments. A potential limitation of the trial was low patient numbers in the CRNP and HIV-AN groups, which prevented meaningful subgroup analyses. This could have been improved with stratified sampling to increase recruitment in the subgroups. In addition, controlling for longitudinal change in concomitant medication was not possible in this study and could have affected the outcomes reported with the capsaicin $8 \%$ patch.

\section{Conclusions}

In conclusion, the use of the capsaicin $8 \%$ patch in a real-world, clinical practice setting provided rapid pain relief in patients with various PNP aetiologies. The response to initial treatment and re-treatment was sustained as evidenced by the maintenance of treatment response with re-treatment intervals averaging over 26 weeks. The capsaicin $8 \%$ patch was generally well tolerated, usually required less than two patches per treatment, and improved overall HRQoL. Patients in the primary stage of treatment or with short duration of disease had the greatest pain reduction suggesting that patients with PNP may benefit from early treatment with the capsaicin $8 \%$ patch. In addition, the capsaicin $8 \%$ patch may benefit patients who have inadequate pain relief from systemic therapies or for those suffering intolerable systematic side effects.

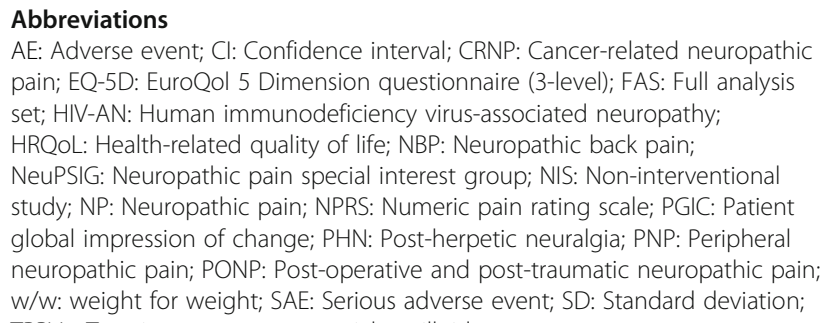

Abbreviations

AE: Adverse event; Cl: Confidence interval; CRNP: Cancer-related neuropathic pain; EQ-5D: EuroQol 5 Dimension questionnaire (3-level); FAS: Full analysis set; HIV-AN: Human immunodeficiency virus-associated neuropathy; HRQoL: Health-related quality of life; NBP: Neuropathic back pain; NeuPSIG: Neuropathic pain special interest group; NIS: Non-interventional study; NP: Neuropathic pain; NPRS: Numeric pain rating scale; PGIC: Patient global impression of change; PHN: Post-herpetic neuralgia; PNP: Peripheral neuropathic pain; PONP: Post-operative and post-traumatic neuropathic pain; w/w: weight for weight; SAE: Serious adverse event; SD: Standard deviation; TRPV1: Transient receptor potential vanilloid type 1

\section{Acknowledgements}

Medical writing support was provided by Kinnari Patel of Bioscript Group, which was funded by Astellas Pharma Europe Ltd.

\section{Funding}

This study and medical writing and editing services were funded by Astellas Pharma Europe Ltd.

\section{Availability of data and materials}

The datasets generated during and/or analysed during the current study are available at www.clinicaltrials.gov using accession number NCT01737294.

\section{Authors' contributions \\ CM, CDP and IO participated in the concept and design of the study. $R T, E B, E E$ and CJC performed the analyses. CT was responsible for medical oversight of the study, and review of clinical data and study reporting. JIC, CP and EZ recruited patients and acquired data. All provided critical revision of the publication for intellectual content. All authors read and approved the final manuscript.}

\section{Competing interests}

$\mathrm{CM}$ and EE are employed by Astellas. $1 \mathrm{O}$ was employed by Astellas at the time of the study. CDP was employed by Astellas at the time of analysis and is now employed by Digital Health Labs Ltd. CT is employed by Astellas as a contractor. RT and EB are employed by Pharmatelligence. EZ was employed at Evangelismos General Hospital until the completion of the study and is now employed by Novartis (Hellas) S.A.C.I. CJC, JIC and CP have no disclosures.

\section{Consent for publication}

Not applicable.

\section{Ethics approval and consent to participate}

The study protocol was approved by the independent ethics committees of the participating centres and by other agencies applicable to NIS as per local requirements. Patients provided written informed consent for participation in the study.

\section{Publisher's Note}

Springer Nature remains neutral with regard to jurisdictional claims in published maps and institutional affiliations.

\section{Author details}

${ }^{1}$ Astellas Pharma Europe Ltd, 2000 Hillswood Drive, Chertsey KT16 OPS, UK.

${ }^{2}$ Astellas Pharma Europe B.V., Leiden, The Netherlands. ${ }^{3}$ Pharmatelligence,

Cardiff, UK. ${ }^{4}$ Cardiff University, Cardiff, UK. ${ }^{5}$ Complejo Hospitalario de Navarra,

Pamplona, Spain. ${ }^{6}$ Evangelismos General Hospital, Athens, Greece.

Received: 23 August 2016 Accepted: 13 March 2017

Published online: 21 April 2017

References

1. Treede RD, Jensen TS, Campbell JN, Cruccu G, Dostrovsky JO, Griffin JW, et al. Neuropathic pain: redefinition and a grading system for clinical and research purposes. Neurology. 2008;70(18):1630-5.

2. Marchettini P, Lacerenza M, Mauri E, Marangoni C. Painful peripheral neuropathies. Curr Neuropharmacol. 2006;4(3):175-81.

3. Torrance N, Smith BH, Bennett MI, Lee AJ. The epidemiology of chronic pain of predominantly neuropathic origin. Results from a general population survey. J Pain. 2006;7(4):281-9.

4. Bouhassira D, Lanteri-Minet M, Attal N, Laurent B, Touboul C. Prevalence of chronic pain with neuropathic characteristics in the general population. Pain. 2008;136(3):380-7.

5. Doth AH, Hansson PT, Jensen MP, Taylor RS. The burden of neuropathic pain: a systematic review and meta-analysis of health utilities. Pain. 2010; 149(2):338-44.

6. Finnerup NB, Attal N, Haroutounian S, McNicol E, Baron R, Dworkin RH, et al. Pharmacotherapy for neuropathic pain in adults: a systematic review and meta-analysis. Lancet Neurol. 2015;14(2):162-73.

7. Haanpää M, Treede RD. Neuropathic Pain. In Lynch ME, Craig KD \& Peng PWH (eds). Clinical pain management: a practical guide. Oxford: Wiley-Blackwell; 2010: 281-9.

8. Wallace JM. Update on pharmacotherapy guidelines for treatment of neuropathic pain. Curr Pain Headache Rep. 2007;11(3):208-14.

9. Gahr M, Freudenmann RW, Hiemke C, Kolle MA, Schonfeldt-Lecuona C. Pregabalin abuse and dependence in Germany: results from a database query. Eur J Clin Pharmacol. 2013;69(6):1335-42. 
10. Anand P, Bley K. Topical capsaicin for pain management: therapeutic potential and mechanisms of action of the new high-concentration capsaicin 8\% patch. Br J Anaesth. 2011;107(4):490-502.

11. Uceyler N, Sommer C. High-dose capsaicin for the treatment of neuropathic pain: what we know and what we need to know. Pain Ther. 2014;3(2):73-84

12. Backonja M, Wallace MS, Blonsky ER, Cutler BJ, Malan Jr P, Rauck R, et al. NGX-4010, a high-concentration capsaicin patch, for the treatment of postherpetic neuralgia: a randomised, double-blind study. Lancet Neurol. 2008;7(12):1106-12.

13. Clifford DB, Simpson DM, Brown S, Moyle G, Brew BJ, Conway B, et al. A randomized, double-blind, controlled study of NGX-4010, a capsaicin 8\% dermal patch, for the treatment of painful HIV-associated distal sensory polyneuropathy. J Acquir Immune Defic Syndr. 2012;59(2):126-33.

14. Irving GA, Backonja MM, Dunteman E, Blonsky ER, Vanhove GF, Lu SP, et al. A multicenter, randomized, double-blind, controlled study of NGX-4010, a high-concentration capsaicin patch, for the treatment of postherpetic neuralgia. Pain Med. 2011;12(1):99-109.

15. Maihofner C, Heskamp ML. Prospective, non-interventional study on the tolerability and analgesic effectiveness over 12 weeks after a single application of capsaicin 8\% cutaneous patch in 1044 patients with peripheral neuropathic pain: first results of the QUEPP study. Curr Med Res Opin. 2013;29(6):673-83.

16. Simpson DM, Brown S, Tobias J, the NGX-4010 C107 Study Group Controlled trial of high-concentration capsaicin patch for treatment of painful HIV neuropathy. Neurology. 2008;70(24):2305-13.

17. Stoker M, Katz N, Van J, Snijder R, Jacobs H, Long S, et al. Capsaicin 8\% patch in painful diabetic peripheral neuropathy: a randomised, doubleblind, placebo-controlled study. Diabetologia. 2015;58(Suppl. 1):S32.

18. Haanpää M, Cruccu G, Nurmikko TJ, McBride WT, Docu Axelarad A, Bosilkov A, et al. Capsaicin 8\% patch versus oral pregabalin in patients with peripheral neuropathic pain. Eur J Pain. 2016;20(2):316-28.

19. Maihofner CG, Heskamp ML. Treatment of peripheral neuropathic pain by topical capsaicin: Impact of pre-existing pain in the QUEPP-study. Eur J Pain. 2014;18(5):671-9.

20. European Medicines Agency. Qutenza Product Information. Annex 1: Summary of product characteristics. 2015. Available at: http://www.ema. europa.eu/docs/en_GB/document_library/EPAR__Product_Information/ human/000909/WC500040453.pdf.

21. Farrar JT, Young Jr JP, LaMoreaux L, Werth $J$, Poole RM. Clinical importance of changes in chronic pain intensity measured on an 11-point numerical pain rating scale. Pain. 2001;94(2):149-58.

22. Rabin R, de Charro F. EQ-5D: a measure of health status from the EuroQol Group. Ann Med. 2001;33(5):337-43.

23. Dolan P. Modeling valuations for EuroQol health states. Med Care. 1997; 35(11):1095-108.

24. Hurst $\mathrm{H}$, Bolton J. Assessing the clinical significance of change scores recorded on subjective outcome measures. J Manipulative Physiol Ther. 2004:27(1):26-35.

25. Grant MD, Samson D. Special report: measuring and reporting pain outcomes in randomized controlled trials. Technol Eval Cent Assess Program Exec Summ. 2006;21(11):1-2.

26. Walters SJ, Brazier JE. Comparison of the minimally important difference for two health state utility measures: EQ-5D and SF-6D. Qual Life Res. 2005; 14(6):1523-32

27. Anastassiou E, latrou CA, Vlaikidis N, Vafiadou M, Stamatiou G, Plesia E, et al. Impact of pregabalin treatment on pain, pain-related sleep interference and general well-being in patients with neuropathic pain: a non-interventional, multicentre, post-marketing study. Clin Drug Investig. 2011;31(6):417-26.

28. Markley HG, Dunteman ED, Kareht S, Sweeney M. Real-world experience with once-daily gabapentin for the treatment of postherpetic neuralgia (PHN). Clin J Pain. 2015;31(1):58-65.
29. Simpson DM, Robinson-Papp J, Van J, Stoker M, Jacobs H, Snijder RJ, et al. Capsaicin 8\% patch in painful diabetic peripheral neuropathy: a randomized, double-blind, placebo-controlled study. J Pain. 2017;18(1):42-53.

30. Vinik Al, Perrot S, Vinik EJ, Pazdera L, Jacobs H, Stoker M, Long SK, Snijder RJ, van der Stoep M, Ortega E, Katz N. Capsaicin 8\% patch repeat treatment plus standard of care (SOC) versus SOC alone in painful diabetic peripheral neuropathy: a randomised, 52-week, open-label, safety study. BMC Neurol. 2016;16:251.

31. Simpson DM, Brown S, Tobias JK, Vanhove GF, the NGX-4010 C107 Study Group. NGX-4010, a capsaicin 8\% dermal patch, for the treatment of painful HIV-associated distal sensory polyneuropathy: results of a 52-week openlabel study. Clin J Pain. 2014;30(2):134-42.

\section{Submit your next manuscript to BioMed Central and we will help you at every step:}

- We accept pre-submission inquiries

- Our selector tool helps you to find the most relevant journal

- We provide round the clock customer support

- Convenient online submission

- Thorough peer review

- Inclusion in PubMed and all major indexing services

- Maximum visibility for your research

Submit your manuscript at www.biomedcentral.com/submit
Biomed Central 